\title{
Life cycle inventory data for the Italian agri-food sector: background, sources and methodological aspects
}

\author{
B. Notarnicola ${ }^{1}$ - G. Tassielli ${ }^{1}$ P. A. Renzulli ${ }^{1}$ (I) R. Di Capua ${ }^{1}$ - G. Saija ${ }^{2} \cdot$ R. Salomone ${ }^{2} \cdot$ P. Primerano ${ }^{2} \cdot$ L. Petti $^{3}$.

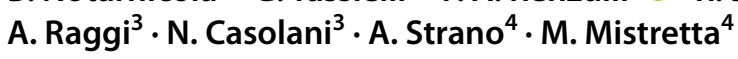

Received: 19 October 2021 / Accepted: 21 December 2021

(c) The Author(s) 2022

\begin{abstract}
Purpose For the development of any life cycle assessment study, the practitioner frequently integrates primary data collected on-field, with background data taken from various life cycle inventory databases which are part of most commercial LCA software packages. However, such data is often not generally applicable to all product systems since, especially concerning the agri-food sector, available datasets may not be fully representative of the site specificity of the food product under examination. In this context, the present work investigates the background, sources and methodological aspects that characterise the most known commercial databases containing agri-food data, with a focus on four agri-food supply chains (olive oil, wine, wheat products and citrus fruit), which represent an important asset for the Italian food sector.

Methods Specifically, the paper entails a review of currently available LCI databases and their datasets with a twofold scope: firstly, to understand how agri-food data is modelled in these databases for a coherent and consistent representation of regional scenarios and to verify whether they are also suitable for the Italian context and, secondly, to identify and analyse useful and relevant methodological approaches implemented in the existing LCI databases when regional data are modelled. Results Based on the aforementioned review, it is possible to highlight some problems which may arise when developing an LCI pertaining to the four Italian agri-food supply chains, namely:

1. The need for specific inventory datasets to tackle the specificities of agri-food product systems.

2. The lack of datasets, within the existing DBs, related to the Italian context and to the abovementioned supply chains. In fact, at present, in the currently available LCI DBs, there are very few (or in some cases none) datasets related to Italian wine, olive oil, wheat-based products and citrus fruit. The few available datasets often contain some data related to the Italian context but also approximate data with that of product systems representing other countries.

Furthermore, the present study allowed to identify and discuss the main aspects to be used as starting elements for modelling regional data to be included in a future Italian LCI database of the abovementioned four supply chains.

Conclusions The results of the present study represent a starting point for the collection of data and its organisation, in order to develop an Italian LCI agri-food database with datasets which are representative of the regional specificities of four agrifood supply chains which play an important role in the Italian economy.
\end{abstract}

Keywords Life cycle assessment $($ LCA $) \cdot$ LCI data $\cdot$ Pasta $\cdot$ Bread $\cdot$ Olive oil $\cdot$ Wine $\cdot$ Citrus fruit

\section{Introduction}

One of the fundamental methods connected with the implementation of the EU Integrated Product Policy (Heijungs et al. 2006) is life cycle assessment (LCA) (ISO 2006a,

Communicated by Elena Neri.

P. A. Renzulli

pietro.renzulli@uniba.it

Extended author information available on the last page of the article 2006b) which is used to evaluate the environmental profile of product systems, including that of agri-food (Notarnicola et al. 2015).

Typically, for the development of any LCA study, the practitioner will inevitably face the need to use reliable and accurate inventory data that, for the primary object and processes under study (the foreground system), will be collected on-field. Such data will be integrated with that of the upstream and downstream life cycle phases (the background system), which are often taken from databases (DBs), in 
which data quality plays a fundamental role and affects the overall results of the study (Guinée et al. 2002).

Thus, in order to meet the necessity for life cycle inventory (LCI) background data, various DBs have been developed and are part of most commercial LCA software packages. These DBs, in the past, have mainly referred to industrial processes with little focus on agricultural processes (Notarnicola et al. 2012). More recently, due to the growing application of LCA to agri-food systems, various initiatives have been developed to provide more LCAs of the agri-food process to LCA practitioners. The need for agrifood DBs has also grown due to the widespread use of Environmental Product Declarations (EPDs) (ISO 2006c) and the more recent Product Environmental Footprint (PEFs) (EU 2013), developed to encourage further use of product environmental schemes in industry. In fact, these schemes often require specific inventory data or "selected generic" data which should be associated with no less than $90 \%$ of the overall environmental impact (EPD 2019). Data from DBs is considered a source of "selected generic" data and is thus useful for the development of a declaration.

LCA is standardised according to the ISO 14040/14044 (2006a, b) and by being "primarily a steady state tool"; it does not consider site- and time-specific aspects (Udo de Haes 2006). However, the importance of considering specific inventory data, from a particular region or area, has often been stated in literature especially for the agricultural life cycle phase (Yi et al. 2007; Yang et al. 2018). This LCI specificity, in terms of inputs or emissions, may be due to:

- Geographical/spatial aspects (Dresen and Jandewerth 2012; Pfister and Baumann 2012; Salmon-Monviola et al. 2012; Nitschelm et al. 2016; Maier et al. 2017; Xu and Lan 2017; Hong et al. 2019). Often, datasets found in DBs are insufficient to describe the spatial heterogeneity of a specific product system and it is therefore difficult to account for differences in crop yields of different areas (for example, due to soil type, crop type or geomorphological aspects) or for the differences in characteristics of the emission receiving environment.

- Temporal aspects (Elin Röös et al. 2010; Pfister and Baumann 2012; Pinsonnault et al. 2014; Pfister and Bayern 2014; Maier et al. 2017). The inclusion of such aspects in a dataset can, for example, account for the variability of the agricultural productivity due to seasonal aspects (e.g. different regions, when referring to a particular crop/plant, can have a different number of harvests per year, or a differing lifetime).

- Technological aspects (Balafoutis et al. 2017; Fritter et al. 2020). Non-specific datasets found in DBs may not account for the use of different irrigation systems and soil management practices of a particular context (for example, in terms of machinery use or of different fertiliser or pesticide application approaches) or even of different energy sources used in the agricultural or industrial phases in various regions/nations.

The need for regionalised specific inventory data may depend on certain LCA methodological choices (, Notarnicola et al. 2017; Sala et al. 2017; Gheewala et al. 2020) such as:

- The choice functional unit (FU); for example, choosing an FU based on the protein content of an agri-food product will imply the need for specific LCI information concerning the protein content of the product being analysed. For example, durum wheat from different parts of the world can have different protein contents (Del Nobile et al. 2005).

- The definition of the system boundary and how to deal with allocation will obviously define what data is needed to represent all the life cycle stages included in an LCA study. For example, the inclusion of the use phase of an agri-food product implies the need for specific data on consumer transport, cooking and waste management which may well be different for different geographical regions.

- The choice of pesticide and fertilisation dispersion model (for example, the model of de Beaufort-Langeveld et al. (2003) as opposed to that of Birkved and Hauschild (2006) as far pesticides are concerned) determines what specific emission data will be included in the inventory of an LCA study.

All this considered, it is obvious that inventory data concerning, for example, French or Swiss agri-food systems commonly found in existing DBs (e.g. Agribalyse 2017; Ecoinvent 2021) may be only partially applicable to an Italian context and hence to LCAs of Italian agri-food products. Thus, a national LCI database of agri-food products is needed to account for the specificity (Ruviaro et al. 2012) of Italian food products. Furthermore, considering the relevance of the LCA methodology to the evaluation of circular production models, the creation of a regionalised and sitespecific inventory for Italian agro-food production, which considers all the life cycle phases of the main national supply chains (including waste, by-product and end-of-life management), becomes a fundamental step to support the transition to development models based on the circular economy.

In this context, the goal of this paper is twofold: firstly, understand how agri-food data is modelled in LCI DBs for a coherent and consistent representation of regional scenarios and verify if they are also suitable for the Italian context and, secondly, to identify and analyse useful and relevant methodological approaches implemented in the existing LCI databases. Following this review, with a specific focus only on those elements that can influence the regionalisation of 


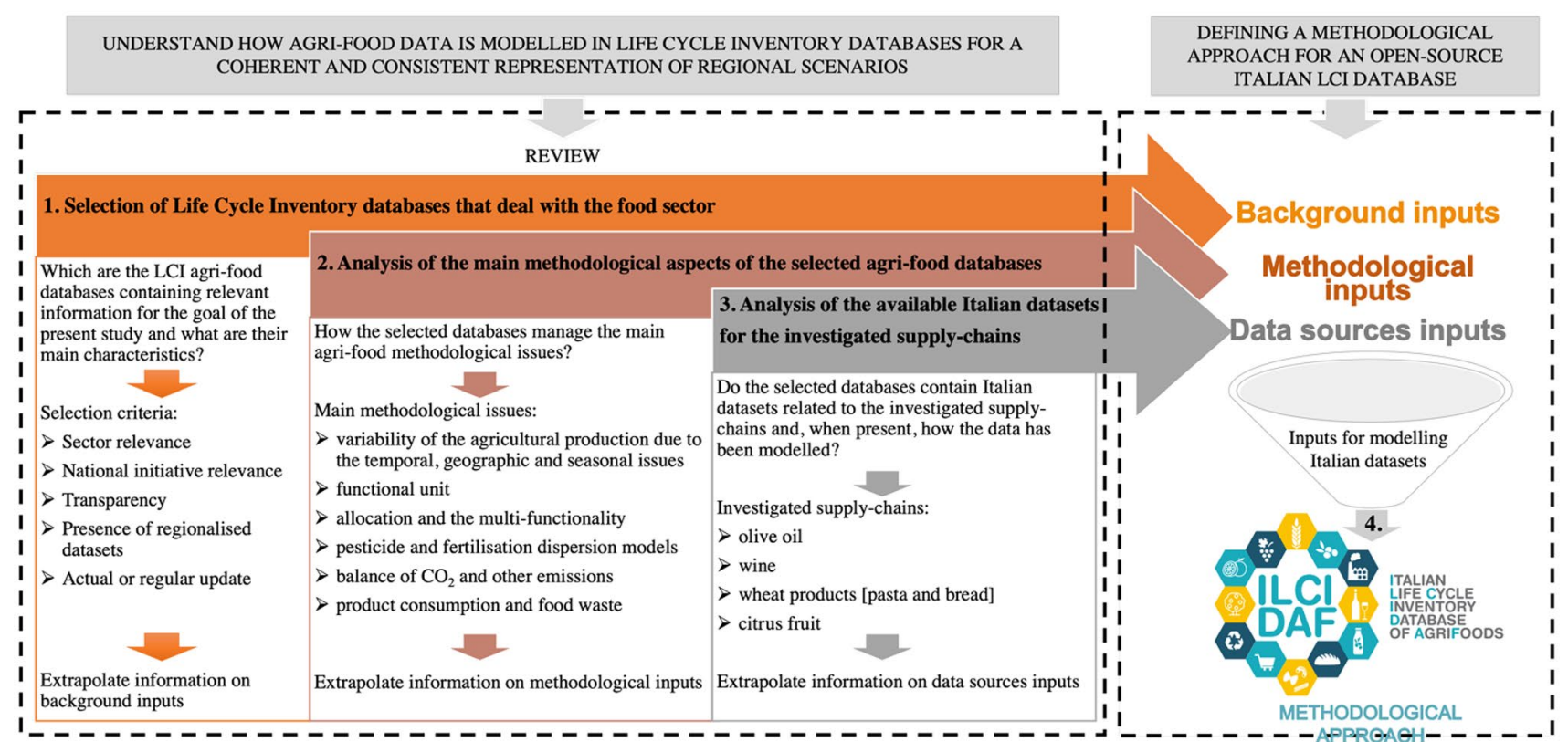

Fig. 1 Summary of the research method: steps and related research questions

data, useful and relevant methodological approaches of the existing LCI DBs are identified in order to use them as building blocks for the future creation of an open-source Italian LCI database (Italian LCI Database of Agri-Food Products [ILCIDAF] project) ${ }^{1}$ of four supply chains (i.e. olive oil, wine, wheat products [pasta and bread] and citrus fruit), which represent an important asset for the Italian agricultural economy (Italy is among the world top producers of pasta, wine and olive oil) (Marras et al. 2020).

This paper is structured as follows. Section 2 explains the research method. Section 3 contains the results of a review and analysis of selected LCI DBs (that deal with the food sector) and of the Italian datasets they contain, pertaining to the abovementioned supply chains. Section 4 illustrates the most useful and relevant methodological approach resulting from the review that will be applied as main pillars of the future ILCIDAF database. Finally, Sect. 5 draws some conclusions.

\section{Research method}

Following the twofold goal of this paper, the adopted research method has been structured in four main steps, as summarised in Fig. 1:

\footnotetext{
1 The open-source Italian LCI database, with the focus on abovementioned agri-food product systems, will be the final deliverable of the ILCIDAF project "Promoting Agri-Food Sustainability: Development of an Italian LCI Database of Agri-Food Products (ILCIDAF)", funded by the Italian the Ministry of University and Research.
}

1. Selection of LCI DBs that deal with the food sector according to criteria coherent with the goal of this study.

2. Analysis of the main methodological aspects of the selected agri-food DBs that may influence the regionalisation of data.

3. Analysis of the available Italian datasets for the investigated supply chains.

4. Identification of the most useful and relevant methodological approaches, with a specific focus only on those elements that can influence the regionalisation of data, to be used as main pillars of the future ILCIDAF.

\subsection{Step 1: Selection of LCI DBs that deal with the food sector}

During the last decades, LCA studies on agri-food chains have increased considerably and, consequently, several LCI DBs have also been developed to support researchers and practitioners in their analysis, but most of these DBs are characterised by a lack of regionalisation (Notarnicola et al. 2015, 2017). This means that, among the various available DBs, a selection of LCI agri-food DBs containing relevant information for the goal of the present study was necessary. The inclusion criteria used for the selection are listed in Table 1 and have been used to identify the most known DBs including agri-food and containing welldocumented methodological information datasets (using user documentation available online and grey-literature technical reports) in order to understand how regional inventory data were modelled. In particular, the main 
characteristics of the selected DBs (such as first release, available versions, process modelling choices, type of agri-food datasets included, extent of regionalisation) were analysed to identify the relevant background inputs that will constitute modelling of general characteristics of the future ILCIDAF datasets.

It should be highlighted that other relevant characteristics of LCI, such as nomenclature and format - e.g. ILCD (EC 2010) or EcoSpold2 (Meinshausen et al. 2016) - that have been already investigated in previous reviews (e.g. Fritter et al. 2020), are out of the scope of the present study because not relevant for the understanding of the modelling of regional inventory data in LCI DBs.

\subsection{Step 2: Analysis of the main methodological aspects of the selected agri-food databases}

The selected DBs are then analysed in order to extrapolate relevant information about how they manage the main methodological issues connected to the agri-food sector; both production and consumption aspects have been considered because they are potentially affected by regional specificities. In particular, information concerning the following aspects, illustrated in Sect. 1 of this paper, is searched for:

- The variability of the agricultural production due to the geographic, temporal and technological specificities, which inevitably affect the environmental profile of such production.

- The functional unit (FU) - e.g. which physical quantity to link it to (mass, volume of product, protein or carbohydrate content of a portion of a product); such choice determines -which specific LCI data is needed.

- Issues concerning allocation and the multi-functionality of food products - typically food production cycles entail the production of by-products and very little waste; allocation issues need to be addressed in such circumstances regarding co-productions with different added values.

- Pesticide and fertiliser dispersion models: these are numerous and need to be carefully chosen (the effects depend on the site-specific variables such as the amount of rainfall and depth of the groundwater level).

- Product consumption - consumer behaviour (which is dependent on specific cultural and social aspects) can determine different LCI data for different regions.

The result of this step is the identification of the main methodological inputs to be used for modelling ILCIDAF datasets.

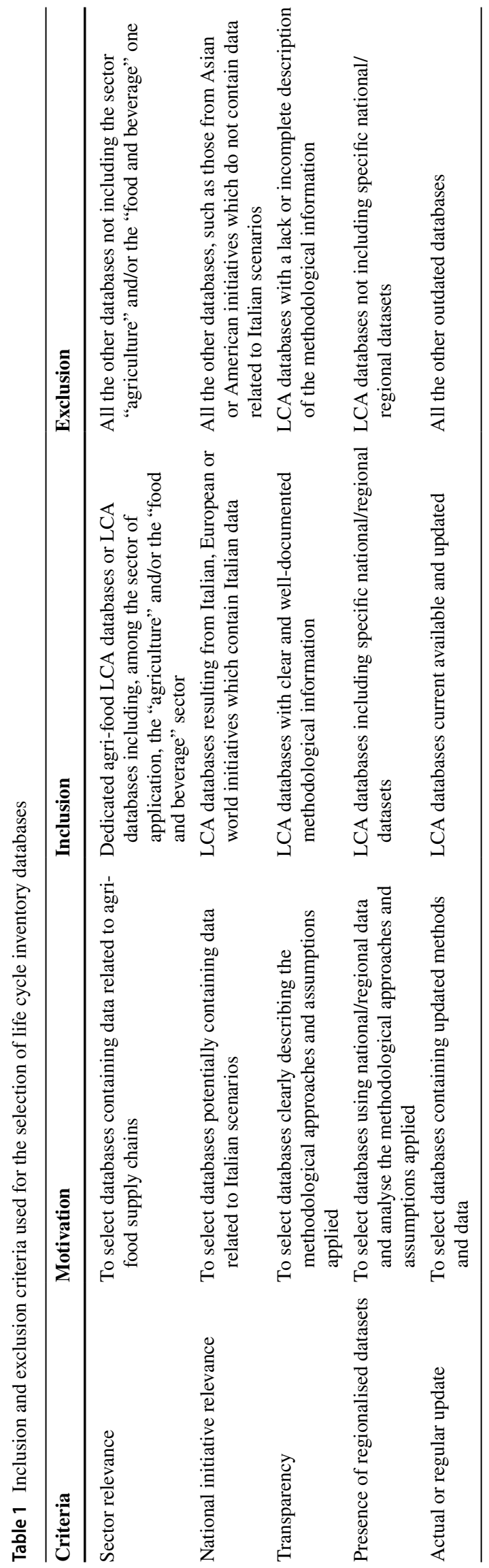




\subsection{Step 3: Analysis of the available Italian datasets for the investigated supply chains}

In this subsequent step, Italian datasets related to the investigated supply chains (olive oil, wine, wheat products and citrus fruit) are specifically searched for within the selected agri-food DBs. If such datasets are found, a detailed analysis about how the data has been modelled is carried out. The result of this step is the identification of the main data source inputs which will be used for modelling ILCIDAF datasets.

\subsection{Step 4: Definition of the methodological approach to be used for the future ILCIDAF}

Finally, as represented in Fig. 1, the useful and relevant inputs collected in the previous three review steps (background, methodological and data source information) are used as inputs for defining a methodological approach for regional inventory data to be implemented in a future opensource Italian LCI database of the four analysed supply chains. This methodological approach is therefore presented by comparing it to the main methodological issues of the selected DBs previously analysed.

\section{A review of how agri-food data are modelled in current LCI DBs}

The analysis of existing DBs revealed that the development of LCA inventories concerning agri-food systems has followed two main streams: (i) the first entails the development of specific "food-based" DBs; (ii) the second concerns the addition of data concerning agri-food products to existing generic DBs. The first type includes, for example, the Danish "Food LCA DK" DB (Nielsen et al. 2003), the French "Agribalyse" (2017) DB and the Dutch DB called "Agrifootprint" (Blonk 2014). Another initiative in the development of a food-based DB is the Swiss project "World Food Database" (Nemecek 2019; Quantis 2020) regarding the food-related process from northern Europe and the USA. The second aforementioned path of LCI development has given birth to the implementation of a series of food-related datasets in the Swiss "Ecoinvent" DB (Wernet et al. 2016; Ecoinvent 2021) and in that of the "Gabi" software (Kupfer et al. 2020). The development of these DBs has taken place mainly to represent the characterisation needs of a specific territory, at times via the subsidisation from several national ministries, and at present has not brought about an Italian agri-food inventory DB.

Starting from an update of the list of LCI DBs for the agri-food sector published in Notarnicola et al. (2015), and after having applied the selection criteria described in
Table 1, five DBs were identified for the inclusion in the research presented here, namely:

- Agribalyse

- French LCI database for agricultural products established in 2010 following the "Grenelle de l'Environnement" event (organised by the French Ministry of the Environment). The latest version of Agribalyse, 3.0, built on the previous versions, was published in 2020 (Koch and Salou 2020); it presently comprises LCIs for 2500 agricultural and food products that are produced and/or consumed in France and combines a production-based approach with a consumption-based approach.

- Agri-footprint (AFP)

- Developed by Blonk Consultants, AFP was released in 2014, and today it is updated to its 5 th version. The DB is based on an attributional approach, aimed to support micro-level decision support and accounting applications (A and C) according to the classification proposed by the ILCD guidelines (JRC 2010). The Agri-footprint DB includes inventory data on agricultural and livestock products, agri-foodstuffs, animal feed and intermediate products.

- Ecoinvent

- The Swiss Centre for Life Cycle Inventories launched the project Ecoinvent in 2000 with the goal to generate a set of generic, consistent, transparent and high-quality LCI data, valid for Swiss and other European countries (Frischknecht et al. 2005). The first version of the Ecoinvent datasets (Ecoinvent Data v1.01) was released in 2003; today it is updated to version 3.7.1 released in December 2020 (Ecoinvent 2021).

\section{- LCA Food DK}

- The "LCA Food database", also known as "LCA Food DK", was released in 2006 as a result of the Danish project "Life Cycle Assessment of Basic Food". This DB, to be used for the quantification the environmental impacts of basic food products produced and consumed in Denmark, covers all steps from agriculture and fishery through industrial food processing to retail and cooking. The DB is based entirely on consequential modelling according to the ISO 14040 series (ISO 14040 2006a), including those processes that are influenced by a marginal change in demand, and uses system expansion to model the emissions related to co-products. 
Table 2 Italian datasets (related to product systems concerning wine, olive oil, wheat bread and pasta products and citrus fruit) that are present in currently available LCA DBs

\begin{tabular}{|c|c|c|c|c|c|c|}
\hline \multirow[t]{2}{*}{ No. of datasets for each supply chain } & \multicolumn{6}{|l|}{ Database } \\
\hline & $\begin{array}{l}\text { Agri } \\
\text {-footprint } \\
\text { v4.0 }\end{array}$ & $\begin{array}{l}\text { LCA } \\
\text { FOOD } \\
\text { DK }\end{array}$ & $\begin{array}{l}\text { Ecoinvent } \\
\text { v3.0 }\end{array}$ & $\begin{array}{l}\text { Agribalyse } \\
\text { v3.0 }\end{array}$ & $\begin{array}{l}\text { WFLDB } \\
\text { v3.5.1 }\end{array}$ & Total \\
\hline Wheat-based products (no. of total datasets) & 236 & 48 & 23 & 50 & 64 & 421 \\
\hline $\begin{array}{l}\text { Wheat-based products (no. of datasets related to Italian product sys- } \\
\text { tems) }\end{array}$ & 6 & $\mathbf{0}$ & $\mathbf{0}$ & $\mathbf{0}$ & 3 & 9 \\
\hline Olive oil (no. of total datasets) & 0 & 0 & 4 & 1 & 5 & 10 \\
\hline Olive oil (no. of datasets related to Italian product systems) & $\mathbf{0}$ & $\mathbf{0}$ & 1 & $\mathbf{0}$ & 1 & 2 \\
\hline Wine (no. of total datasets) & 0 & 0 & 2 & 12 & 15 & 29 \\
\hline Wine (no. of datasets related to Italian product systems) & $\mathbf{0}$ & $\mathbf{0}$ & $\mathbf{0}$ & $\mathbf{0}$ & 1 & 1 \\
\hline Citrus fruit (no. of total datasets) & 0 & 0 & 18 & 21 & 33 & 72 \\
\hline Citrus fruit (no. of datasets related to Italian product systems) & $\mathbf{0}$ & $\mathbf{0}$ & $\mathbf{0}$ & $\mathbf{0}$ & $\mathbf{0}$ & $\mathbf{0}$ \\
\hline Total datasets per database & 236 & 48 & 47 & 84 & 117 & 532 \\
\hline Total Italian datasets per database & 6 & $\mathbf{0}$ & 1 & $\mathbf{0}$ & 5 & 12 \\
\hline
\end{tabular}

\section{- World Food LCA Database (WFLDB)}

- Developed through the collaboration of Quantis and Agroscope since 2012, the WFLDB was released in 2013 and updated in 2019 with version 3.5. This DB is centred on an attributional approach, being based on average and generic data aimed to represent current technologies, in accordance with ILCD goal situation C1 (JRC 2010).

Detailed information regarding the analysis of methodological aspects of the DBs is reported in the Supplementary Material (Appendixes A-E).

\subsection{Analysis of the available Italian datasets}

By analysing the currently available LCI datasets (532 in total), contained in the abovementioned selected DBs and which are related to the supply chains that are object of the present work, it emerges that there are only 12 datasets specifically related to Italian product systems. Table 2 summarises the results of the analysis (the 12 datasets related to Italian product systems are italicised).

The 12 abovementioned datasets regard 9 wheat-based product systems, 2 olive oil product systems and 1 wine product system. No datasets concerning Italian citrus product systems were identified within the DBs.

Of the datasets concerning wheat-based product systems, six are from the Agri-footprint DB and regard the production of wheat flour (as well as wheat bran, wheat middlings and feed and wheat germ), the production of wheat starch (as well as bran, wheat gluten, wheat gluten flour), the cultivation of wheat grain, the drying of wheat grain and activity data on the market mix (origin and transport) of raw materials used for processing wheat grain in Italy. Three other datasets regarding Italian wheat-based product systems can be found in the WFLDB. These regard the cultivation of the wheat grain, the production of dried pasta from durum wheat and the milling of durum wheat. These nine datasets pertaining to the wheat-based product systems often are partially based on data (in terms of flow of matter and energy) from other European countries or on generalised models which generate global non-specific data.

Regarding the 2 datasets related to the olive oil product systems, 1 has been identified in Ecoinvent and 1 in WFLDB. Both refer to "olive production at farm" and are substantially the same dataset. Indeed, agricultural data in Ecoinvent v3 partly correspond to the WFLDB (Ecoinvent 2021). The dataset contains data representative of olive production in Italy (Puglia or Sicily) aimed at representing olives produced for the export market. The data refers to an average situation, characterised by $4.3 \mathrm{t} / \mathrm{ha}$ yield for the reference period from 2001 to 2008, in irrigated conditions. The functional unit and system boundaries respectively refer to " $1 \mathrm{~kg}$ of olive" and to a cradle-to-grave approach considering a lifetime of 40 years (250 trees/ha planted). No cut-off has been specified in both the analysed datasets, but, in general, the WFLDB highlights that in crop production systems, processes that can reasonably be assumed to contribute to less than $1 \%$ of the environmental impact are excluded and cut-off criteria are applied only when no data is available. Despite the fact that both olive oil product systems are representative of Italy, the analysis allows defining that, among the input processes and the outputs (considering both emissions and waste) observed in Ecoinvent and WFLDB, only four of them are related to the Italian context ((i) land use change, (ii) irrigation, (iii) waste wood, (iv) water emission). In addition, although four inputs in terms of fertilisers 
are modelled through Pergola et al. (2013), who collected data for an Italian olive orchard management system, they are related to the global geography (GLO).

The only dataset related to Italian wine-based product systems is included in the WFLDB. The dataset refers to the conventional production of "Grape, wine grape, at farm", and it is generated with an average of on-field Italian data from datasets concerning various heterogeneous types of wine grape.

\section{Discussion}

The results of the present study allow to further stress that the future ILCIDAF DB needs to be structured in a manner that will overcome the problem of the non-representativeness (highlighted by the dataset analysis described in the previous section) of other LCA DBs of the specificities of Italian food product systems regarding the wine, olive oil, wheat product (pasta and bread) and citrus fruit supply chains. The following paragraphs critically discuss the results in order to analyse some of the methodological approaches and the data sources that should be considered in the development of this future DB by, whenever appropriate, comparing these to the existing DBs.

\subsection{General principles concerning the data sources and their representativeness}

\subsubsection{Main international databases}

When considering the geographical and technological representativeness of national datasets, in particular those regarding crop production, existing DBs, in general, generate data according to a hierarchical model in order to provide for each input the highest possible quality data level available.

Specifically, the WFLDB rates the data on five levels of detail where the highest quality is that of originating from literature or expert data with a high level of detail. This is followed by data from literature or expert data with a medium level of detail. These are followed by two levels of data originating from statistical sources and finally proxy data. Typically, national/regional datasets are obtained from statistical data.

The Agribalyse DB generates its national datasets by using directly statistical data, or that originating from expert opinion or literature or by averaging several individual datasets of different geographical area (i.e. different French regions).

The Agri-footprint DB documentation indicates that data is derived from documented expert data or from statistics and data gaps are filled with best available data (proxy data), but no specific indication is given on how national or regional datasets are obtained.

In the LCA Food DK DB, data on processes in the food sector are collected from different statistical sources and on-field. Some processes are determined by a "top-down" approach by "dissecting" national statistical data to represent specific processes. Other process data have been determined by a "bottom-up" approach, through which data from a limited number of sources have been used to represent the national level.

The Ecoinvent DB uses data from official statistics, expert data, literature and estimates when no other source of information is available. There is no indication on a hierarchical model used for data representativeness selection, and no specific indication is given on how national or regional datasets are obtained.

\subsubsection{ILCIDAF DB}

In terms of representativeness (i.e. Italian context) of the data, comprising the datasets developed for the future ILCIDAF DB, four levels of representativity are defined, namely:

- National average, based on on-field data

This data is on-field/literature data from one or more sources (e.g. consortiums) which represent at least $50 \%$ of the overall Italian production occurring in the process described in a dataset.

This type of approach for the generation of LCI data (whenever available) is that which is used for the Agribalyse DB, which aims to provide datasets for agricultural products representative of the French market.

\section{- National average, based on statistical data}

This data is that arising from Italian statistical sources. Such data is representative of at least $80 \%$ of the national production of raw materials and finished products. In this case, the starting point for the generation of datasets is a national statistical study to identify the main production regions of each type of product (olive oil, wine, wheat-based products and citrus fruit).

For products such as pasta, which also involve agricultural products originating from abroad, statistical data is also used (whenever possible) for the quantification of yields, fertiliser and pesticide use such as that found in the EC feed DB (FEFAC 2015), FAO (2015) and IFA (2020). This statistical approach for the generation of LCI data is also implemented, as an alternative to specific onsite data collection, in all other existing DB. 
- National, based on on-field data

This data is on-field/literature data from one or more sources which represent a small share (less than $10 \%$, e.g. a local/regional product system) of the overall Italian production occurring in a process described in the dataset.

The use of national on-field data is also implemented in the Agribalyse DB for generating LCI datasets for the same product, for different farming practices or regions.

- Generic, based on data not originating from Italy

This data is any kind of data which does not refer to an Italian product system which is used as a proxy when no other data is available. Specifically, in case of unavailable primary data or scientific literature data, the ILCIDAF data is constructed by basing it on the analogies with similar products, for example, those which share analogous cultivation or extraction processes. Such approach for the construction of DBs is recommended in the ISO 14044 standard.

As with all commercially available DBs, for the generation of the LCI data, a reference period of several years will be used to account for the temporal variability. In particular, in the ILCIDAF DB, to account for the temporal variability concerning certain data sources, such as the national electricity mix, crop yields, fertiliser and pesticide use, whenever possible, inventory data from the period 2016-2020 will be used. Exceptions will be documented in the dataset documentation, and their quality will be evaluated (see Sect. 4.5).

\subsection{Functional unit and system boundary}

The functional unit (FU) to which the datasets refer to, in the ILCIDAF DB, will be as follows:

- For all agricultural datasets (i.e. crop products), the FU will be based on a mass reference of one kilogram $(1 \mathrm{~kg})$ of output fresh product (e.g. $1 \mathrm{~kg}$ of wheat, grapes, oranges.). Whenever possible, the ILCIDAF datasets will provide information on the energy, protein and antioxidant agent content (e.g. olive oil) to allow the LCA practitioner to define other FUs

- For transformed food items such as wheat flour and bread, the FU will refer to a unit of product (e.g. $1 \mathrm{~kg}$ ), unpackaged, at the plant exit gate. In the case of wine, olive oil and pasta, the FU will refer to a unit of packaged product, at the plant exit gate (e.g. one $0.75-\mathrm{L}$ bottle of wine).

- For datasets concerning food transformation activities (e.g. packaging or cooking) and transport. the FU can be an amount of (in terms of mass e.g. $1 \mathrm{~kg}$ ) of input/transported product, a time reference (10-min cooking time) or a unitary reference (e.g. one glass bottle of $0.75 \mathrm{~L}$ ).

All energy sub-datasets contained in the primary datasets concerning energy inputs and outputs will refer to an FU of $1 \mathrm{kWh}$ for electrical energy and $1 \mathrm{MJ}$ of heat energy. All other sub-datasets will refer to mass-based functional units (or volume if appropriate, e.g. $1 \mathrm{~m}^{3}$ of irrigating water).

Concerning the system boundary, some of the existing DBs set it from cradle to gate (Agri-footprint, Agribalyse and Ecoinvent), whilst WFLDB and Food LCA DK also include the use phase (food conservation and preparation). The proposed future ILCIDAF DB intends to also consider the distribution and use phase (whenever appropriate) for the LCI DB development. This entails the development of a model for the distribution of the product to the consumer, the domestic conservation of the food and its cooking procedures (see Sect. 4.4.4). Thus, the DB processes will be modular and the LCA practitioner will be able to choose up to which stage of the life cycle to set up his study and hence use the specific inventory data.

\subsection{Allocation}

The WFLDB, Agribalyse and Agri-footprint DBs implement attributional modelling, with allocation used to deal with multi-functionality whenever system expansion or process subdivision is not implementable. The Food LCA DK DB is based entirely on consequential modelling whilst Ecoinvent allows the user to choose between three different system models: the "allocation, cut-off by classification" using a cut-off approach, the "allocation at the point of substitution" (APOS) using an attributional approach and the "Substitution, consequential, long-term" using a consequential approach (Wernet et al. 2016; Ecoinvent 2021).

The future ILCIDAF DB should be based on attributional modelling and uses, when necessary, mass-based allocation. In cases in which the primary production might bring about the generation of co-products/by-products, for which there may be several potential uses, in accordance to ISO 14044 (2006b), the ILCIDAF DB implements economic allocation criteria. The prices for the allocation calculations will be determined (whenever possible) as average Italian values of the 2016-2020 period.

\subsection{Methodological aspects of each life cycle stage}

As mentioned in Sect. 4.2, the development of the ILCIDAF DB entails a system boundary from cradle to fork (including 
the use phase). The next paragraphs illustrate the principal data sources and methodological aspects of each life cycle stage.

\subsubsection{Agricultural phase}

As regards the agricultural phase, whenever on-field data (see Section 4.1.2) is not available, it is proposed to combine the statistical data (e.g. yields, areas; see next sections) with those described in the regional agricultural specifications (and other regional documents) relating to the quantification of diesel and lubricating oil consumption and to the use of pesticides and fertilisers at the regional level (with a possible calculation of the nitrogen balance for the correction of anomalous data).

The statistical analysis will be conducted, whenever possible, on a 5-year basis (2016-2020) to determine average values that take into account the fluctuation of various factors that may have positively or negatively affected the specific crop production. Such statistical approaches will be applied to all crops related to the productive sectors considered in the project.

4.4.1.1 Crop yield Statistical data on crop yield can be obtained by accessing the Italian statistical database ISTAT (2021). In particular, it is possible to query data concerning a desired crop. For example, for the bread and pasta supply chain, it is possible to extract information on production and durum and soft wheat with specific details on the total cultivated area and harvested production per region. In this way, the regions cumulatively responsible for $80 \%$ of the national production of raw materials and finished products can be identified and a specific inventory (dataset) can be constructed. Furthermore, from these inventories, an average single inventory can be generated which summarises the whole Italian production of a specific product (this might interest the practitioner who needs an average national value).

4.4.1.2 Fertiliser use and related emission calculation With reference to the fertilisers used for each crop, the quantity (in terms of $\mathrm{N}$ nitrogen, $\mathrm{P}_{2} \mathrm{O}_{5}$ phosphoric anhydride and $\mathrm{K}_{2} \mathrm{O}$ potassium oxide) taken into consideration will be those indicated in the integrated production regulations of each Italian region. These provide farm fertilisation plans and information on the maximum quantities of macro-nutrients that can be distributed annually for each crop or crop cycle which farmers must comply with.

For example, for the determination of the fertilisers used in the cultivation of durum wheat, the production specifications of the main production regions can be used to identify the indicated dose. To evaluate the consistency of the data obtained with respect to the production yield of each Italian region, a nitrogen balance test will be carried out which consists of balancing the nitrogen inputs and removals from the wheat crop, following the fertilisation doses, contemplated in the regional regulations. Specifically, the calculation of the nitrogen balance will be based on the difference between the total nitrogen inputs and the total removals that have taken place. The nitrogen contributions are those deriving from atmospheric precipitation (for example, in the case of wheat, a value of $20 \mathrm{~kg} / \mathrm{ha}$ is be assumed), from the previous crop (in the case of wheat estimated at $30 \mathrm{~kg} / \mathrm{ha}$ ), and from organic fertilisation, all of which are deduced from the regional production procedural guidelines, and finally from the mineralisation of the organic substance (e.g. assumed equal to $0 \mathrm{~kg} / \mathrm{h}$ a for wheat). The nitrogen removals are those due to denitrification (e.g. assumed equal to $5 \mathrm{~kg} / \mathrm{ha}$ for wheat), volatilisation (e.g. estimated at $0 \mathrm{~kg} / \mathrm{ha}$ for wheat) and leaching (e.g. estimated at $30 \mathrm{~kg} / \mathrm{ha}$ for wheat) and, finally, those caused by the emissions of ammonia $\left(\mathrm{NH}_{3}\right)$ and nitrous oxide $\left(\mathrm{N}_{2} \mathrm{O}\right)$.

The approach to be used to transform the nutrient supply $\left(\mathrm{N}, \mathrm{P}_{2} \mathrm{O}_{5}\right)$ into a type of fertiliser is similar to that adopted in the Agri-footprint DB, which uses average IFA (IFA 2020) statistical data on regional fertiliser consumption.

The inventory data in the ILCIDAF DB will be derived from that present in literature that is based principally on the work of Kongshaug (1998) and Davis and Haglund (1999).

The IPCC methodology (IPCC 2019) will be used to estimate nitrous oxide $\mathrm{N}_{2} \mathrm{O}$ emissions resulting from the application of fertilisers and $\mathrm{CO}_{2}$ emissions related to the application of lime and urea.

Calculations for $\mathrm{NH}_{3}$ and $\mathrm{NO}_{3}$ emissions are carried out following the approach defined by Brentrup et al. (2000). All volatilised nitrogen is assumed to convert to ammonia, and all escaping nitrogen is assumed to be released as nitrate.

Phosphorus emissions to water will be modelled in the same manner as that used in the WFLDB which uses the emission models SALCA-P (Prasuhn 2006) developed by Agroscope. With such approach, the paths of phosphorus emissions are distinguished in those to the ground and to surface water.

Heavy metal emissions will be modelled according to the SALCA-Heavy metal (Freiermuth 2006) model with data from the same sources defined in the WFLDB reference documentation.

4.4.1.3 Pesticide use and related emission calculation Pesticide consumption can be quantified either by using the specific data reported in regional agricultural sources or agricultural handbooks (e.g. Ribaudo 2017). If no information is found in these documents, the data will be extracted from the European report "The use of plant protection products in the European Union" (EC 2007). This contains data 
on the consumption of pesticides for different crops in various European countries. For the quantitative determination of herbicides, fungicides and insecticides, the report data will be re-parameterised for the total number of pesticides used in Italy for the specific supply chain being studied.

For the estimation of emissions deriving from the application of pesticides, it is assumed that the environmental destination of the active ingredient of the pesticide used is $100 \%$ to the soil (de Beaufort-Langeveld et al. 2003). This assumption is also made for the development of the Agrifootprint, Agribalyse, WFLDB and Ecoinvent DBs (the Food LCA DK DB does not include inventory data on pesticides).

4.4.1.4 On-field fuel and lubricant use In LCA Food DK, data are derived from Western Europe (assuming that Danish agriculture varies only slightly from farm type to farm type and from product to product - less than 5\% in the most extreme cases) and the traction modelling is based on the study by Borken et al. (1999).

In Ecoinvent six classes of agricultural machinery are defined based on information from the Swiss Federal Agricultural Research Stations. Data on mean fuel consumption per hour are taken from Rinaldi and Stadler (2002) whilst the machinery operation time, if not known, is approximated with mean values indicated in the reference documentation.

The reference documentation for the WFLDB reports that for the estimation of data about the total machinery input per hectare for a specific crop and country (but not referring to specific field activities), the Ecoinvent process "Agricultural. machinery, general $(\mathrm{kg})$ " is used as a background dataset. The machinery input is estimated according to the MEXALCA approach (Roches et al. 2010; Nemecek et al. 2012) by using the machinery input according to the intensity index for machinery use in a given country (based on FAOSTAT data). For more specific data on on-field activities, the MEXALCA approach is also applied together with the model by Cranfield (Williams et al. 2006) that takes into account the soil cultivation with increased portion of clay in the soil.

The Agribalyse DB uses the Ecoinvent class of machines to generate machinery datasets. The fuel consumption per hectare for numerous field operations is reported in the reference documentation (no details on the sources of such data are given).

All existing DBs give no particular details, in their reference documentation, on the modelling of lubricating oil use for on-field operations.

With reference to the consumption of fuel and lubricating oil, inventory for the ILCIDAF data will be sourced from literature data, extensively detailed for the crops under study in Ribaudo (2017) and from the Life Cycle Inventory datasets of agricultural machinery (Tassielli et al. 2019). The latter contains data based on the tractors and agricultural tools used for specific crops and for each agricultural operation, diversifying the data by classes of field type. In this way, it is possible to account for both the fuel data linked to the performance of the single agricultural operation and the consumption linked to the number of trips made by farmers to return to the field and complete the specific operation. A distance from farm to field travelled by the tractor (or other agricultural machines) will be assumed to be $2 \mathrm{~km}$ (this same value is also assumed for the WFLDB).

4.4.1.5 Land use and land occupation Analogously to the WFLDB, the ILCIDAF DB will consider land occupation, and land use change (LUC) without distinguishing between direct and indirect LUC. The methodology applied will be that of Ecoinvent 3.0 (Nemecek et al. 2012, 2019), which also relies on the approach defined by the IPCC (1997).

\subsubsection{Industrial transformation phase}

In accordance with the aspects concerning data representativity (see Sect. 4.1), the ILCIDAF data for the industrial transformation phase will be generated either directly via the consultation of Italian operators (to account for technological specificities) or from statistical studies and literature.

\subsubsection{Distribution phase of raw materials, intermediate products and final products}

In the Ecoinvent DB, transports between two process steps of a product system are investigated according to the real market situation by calculating road transport, freight ship and plane travel distances. Since means of transportation and transport distances are often hardly known, for all individual intermediate products, standard distances are applied as reported in the reference documentation. The default transport data are based on transport statistics, according to a methodology developed by Borken and Weidema (2013). The freight transport products describe the transport services in tonne-kilometres with average load factors that include the average share of empty return trips.

The WFLDB reference documentation on the datasets indicates the distances travelled for the distribution phases, which are taken from literature. In some cases, default distances to be used for the formulation of the dataset are indicated. No specific details are given on the actual model used for the distribution phase.

The Agri-footprint DB reference documentation reports some default transport distances to be used for the formulation of datasets when no specific data is available. Furthermore, a generic transport model is reported which is based on the Feedprint model (Vellinga et al. 2013). Domestic distances are based on transport mix from 
Eurostat (tkm travelled per mode for domestic transport tasks). Distance between EU countries is based on country midpoint to midpoint, using an international transport mode mix taken from Eurostat. Distances between European countries and countries outside Europe based on transoceanic freight distances are calculated using a specific website. For the USA, the average distance and transport mix is based on the GREET model (Elgowainy et al. 2013). For countries outside the EU, distances are based on literature or expert judgment.

The Agribalyse DB reference documentation reports that transport data are based on GESTIM analyses (Gac et al. 2010), on the work of Nguyen et al. (2012) and on Ecoinvent "v3 market processes".

In the Food LCA DK DB, all transport is considered one-way (or half of a round trip) and all truck weights provided are full load weights. Data on weights and distances are estimated by consulting experts and/or relevant actors and/or by literature references (Drivsholm et al. 2002 and Frees and Weidema 1998). It is assumed that all transportation processes are $40 \%$ efficient including empty returns.

Whenever specific data is not available, for the quantification of the future ILCIDAF data representing the logistics of the products, statistics (Eurostat, Italian national statistics and the GREET model) of the sale of the product on the international/national market will be used. Both national and international distribution will be considered for wholesale and retail distribution. In particular, the modelling will take into consideration the total sales of the finished product with a national destination and the total sales of finished products destined to those foreign countries which cumulatively represent at least $80 \%$ of international product sales. It is assumed that transports of products destined for the Italian market are made by truck, calculating the distance from the gate to the destination logistics platform(s). For product exports, it will be assumed that, for those countries not connected by land routes, transport is carried out by truck from the company's gate to the nearest port, by sea from the port of origin to the port of destination and by land from the port to the capital of the importing country.

Also, in the distribution phase, the energy consumption associated with the time during which the product is stored in the supermarket will be also taken into account. This aspect will be included in the dataset by using the approach defined for the Danish LCA Food DB, which considers the consumption of electricity associated with products sold in various types of supermarkets.

\subsubsection{Use phase}

The WFLDB covers several cooking modes, commonly seen in western countries, by developing specific datasets regarding baking, frying, boiling, steaming and microwaving. Different energy sources for stoves are assessed: electricity, natural gas and liquefied petroleum gas (LPG). Datasets include parameters in such a way that cooking time, microwave power and volume of boiling water can be customised. Data for refrigerated food storage at consumer home is also included. Modelling is based on data from Sonesson et al. (2003) and Milà i Canals et al. (2008), as well as technical data on cooking appliances.

The Food LCA DK DB includes datasets on home food preparation and conservation. Data on refrigerators and freezers are taken from Danish producers of cooling equipment for private households. The data on cooking appliances and recipes from cooking food are taken from electricity suppliers and the Danish consumer organisations.

For the use phase of the products related to the supply chains under consideration in the development of the ILCIDAF DB, an approach will be used that includes two aspects: transport to the consumer's home (assuming a transport of $4 \mathrm{~km}$ by car dividing the journey by 30 products, which are supposed to be purchased on average) and the actual domestic use of the product (its consumption).

For example, the use phase for the wheat supply chain, in particular for pasta, refers to domestic cooking, whose specific inventory data will be collected and differentiated according to the technology used for cooking and according to the cooking time. Data will be taken from stove producers and specific literature from pasta producers.

The consumption of bread, olive oil and citrus fruit consists of absorption in the consumer's diet, and do not require any kind of material and/or energy input. As regards wine, refrigeration at home before actual consumption will be considered for certain wines (e.g. sparkling and still white wines).

\subsubsection{Waste and losses along the supply chain}

A further aspect considered is that relating to the percentage of losses along the life cycle of the product. In this regard, the ILCIDAF will consider the model by Gustavsson et al. (2013), relating to the methodology of the FAO study "Global Food Losses and Food Waste for Europe" (FAO 2011), which defines the percentages of loss in the various stages of the life cycle. The data refer to groups of raw materials and not to individual products. For wheat, for example, the cereal category was taken, whose losses were quantified as follows:

- Agricultural phase: $2 \%$

- Collection and storage phase: $4 \%$

- Industrial phase and packaging: $0.5-0.10 \%$

- Distribution phase: $2 \%$

- Consumption phase: $25 \%$ 


\subsubsection{End of life and circular economy strategies}

Like most of the existing DBs, for the ILCIDAF, the end-oflife modelling will be carried out according to statistical data pertaining to the scenario being modelled. The end-of-life scenario of Italian food waste will be evaluated starting from the data on waste disposal in the EU based on the Eurostat DB, which contains statistics on "Waste treatment [env wastrt]". Specifically, two categories of waste are included in the analysis, namely category W091 "Waste of animal and mixed origin" and W092 "Vegetable waste" for Italy.

The waste deriving from the supply chains under study will be modelled as follows:

- $8 \%$ of food waste disposed of in landfills

- $5 \%$ to incineration

- $87 \%$ to other recovery treatments

Since this recovery treatment is assumed to be composed of $80 \%$ composting and $20 \%$ anaerobic digestion for biogas production (Jungbluth et al. 2007), it is estimated that 69.6\% of the total waste is composted, whilst $17.4 \%$ is digested anaerobically. The models used for the generation of inventory data of such treatments will be those reported in the Ecoinvent v.3 DB.

Regionalising food waste treatment scenarios is also fundamental for defining specific circular economy (CE) strategies at the local level. As pointed out by Roos Lindgreen et al. (2021), LCA may be considered a suitable method for measuring circularity and its related environmental consequences. In this context, a dedicated and specific LCI for the end of life is needed in order to support the transition of local businesses towards CE.

As pointed out by Notarnicola et al. (2017), LCA can help evaluate common CE strategies related to waste management activities in the agri-food sector, such as nutrient recovery, reuse of treated wastewater or reduction of food losses at production, distribution, retail and consumer levels.

Despite this, regardless of the sector of application, some methodological issues may occur when the LCA method is implemented, in the field of CE, to evaluate closed- or openloop strategies for end-of-life activities. Although LCA may help to solve the trade-offs among various ways to close (or open) the resource loops, the modelling of a dedicated LCI for the end-of-life phase does not allow taking into consideration the differences in terms of quality and physical properties between primary and secondary products (i.e. downgrading) (Roos Lindgreen et al. 2021; Niero and Olsen 2016). This may lead to partial results that could highlight a potential environmental benefit without considering the lost quality value of the secondary product. To correctly evaluate the end-of-life strategies, by following the CE framework, a qualitative analysis focused on both primary and secondary materials should be integrated to the LCA method in order to develop an appropriated LCI. In this context, the PEF methodology introduced a specific end-of-life formula, including the downgrading factor, for calculating differences in terms of quality between secondary and primary materials (Niero and Olsen 2016; Allacker et al. 2014).

\subsection{Data quality}

As with all existing DBs (with the exception of the Food LCA DK DB, which checks the representativity and the quality of the datasets by using a method developed by the Danish Research Institute of Food Economics), for the ILCIDAF DB, the quality datasets will be evaluated using a specific "pedigree matrix" (Weidema and Wesnæs 1996). This comprises the definition of the most appropriate quality requisites to be used in the matrix, such as geographic, temporal, technological coverage, completeness and coherence with the methodology and validity of the assumptions and hypotheses of the project. The evaluation of the dataset will be obtained by calculating an overall Data Quality Requirement (DQR) by applying the criteria (including an evaluation of data precision/uncertainty) described in annex II of the Product Environmental Footprint (PEF) guide of the EU Commission recommendation (EU 2013).

\section{Conclusions}

The results of the present study allowed to identify and discuss the main aspects to be used as starting elements for modelling regional data to be included in the future ILCIDAF DB. In particular, the discussion here presented addresses the problems which may arise when developing an LCI pertaining to four Italian agri-food supply chains which are strategic for the Italian economy. Such problems relate to:

1. The need for specific inventory datasets to tackle the specificities of agri-food product systems.

2. The lack of datasets, within the existing DBs, related to the Italian context and to the abovementioned supply chains. In fact, at present, in the currently available LCI DBs, there are very few (or in some cases none) datasets related to Italian wine, olive oil, wheat-based products and citrus fruit. The few available datasets often contain some data related to the Italian context but also approximate data with that of product systems representing other countries.

To fill this gap, in terms of representative Italian datasets, the ILCIDAF DB will use, whenever possible, data (on-field and/or statistical data) and methodological 
approaches (which partially derive from the review of the currently available LCI DBs) to represent as fully as possible the current overall national scenario of the abovementioned product systems. Thus, the development of this Italian DB is intended to improve the advancement of research regarding the environmental analysis of Italian agri-food systems allowing LCA analysts and practitioners to carry out studies which will lead more easily to realistic and representative results.

This, from a technological point of view, together with the fact that the ILCIDAF DB will be an open source of data, will encourage the development of new Italian LCAs, which will in turn increase the number of datasets, thus generating a virtuous circle which will help the development of LCA and its aims. To comprehend such technological impact properly, it is necessary to consider the French situation: the Grenelle 2 law (concerning national commitment to environmental aspects), presented in 2009, introduces the compulsory exhibition on a food product label of the $\mathrm{CO}_{2}$ eq. content referred to the whole product life cycle (including the effects of packaging). In order to allow French companies to adhere to such a law, the national Agribalyse DB was created. In Italy, the introduction of a national food LCA DB is also strongly expected to encourage a sustainable development of the Italian economy.

From a production point of view (considering the vast number of small and medium Italian food enterprises), the ILCIDAF DB represents a useful instrument for an easier obtainment of an EPD (Italy, in fact, is among the countries with the highest number of EPDs) or the more recent PEF-certified declarations.

Finally, in order to guarantee the maximum widespread availability of the open-source DB, its methodology and structure is currently being developed so that it will be possible to integrate the final product easily in the most commonly used LCA software packages. Furthermore, the future integration in the ILCIDAF DB of other agri-food product categories on behalf of any research group wishing to expand the datasets will be made possible by this approach.

Supplementary Information The online version contains supplementary material available at https://doi.org/10.1007/s11367-021-02020-x.

Funding This article is part of the results of the research project "Promoting Agri-Food Sustainability: Development of an Italian LCI Database of Agri-Food Products (ILCIDAF)" (PRIN - Progetti di Ricerca di Interesse Nazionale 2017- Prot. 2017EC9WF2, settore ERC SH2, Linea $\mathrm{C}$ - funded by the Ministry of University and Research).

Data availability All data generated or analysed during this study are included in this published article and its Supplementary Material files.

\section{Declarations}

Conflict of interest The authors declare no competing interests.

Open Access This article is licensed under a Creative Commons Attribution 4.0 International License, which permits use, sharing, adaptation, distribution and reproduction in any medium or format, as long as you give appropriate credit to the original author(s) and the source, provide a link to the Creative Commons licence, and indicate if changes were made. The images or other third party material in this article are included in the article's Creative Commons licence, unless indicated otherwise in a credit line to the material. If material is not included in the article's Creative Commons licence and your intended use is not permitted by statutory regulation or exceeds the permitted use, you will need to obtain permission directly from the copyright holder. To view a copy of this licence, visit http://creativecommons.org/licenses/by/4.0/.

\section{References}

Agribalyse (2017) Database v1.3, France: ADEME. www.ademe.fr/ agribalyse-en. Accessed on 15 April 2021

Allacker K, Mathieux F, Manfredi S, Pelletier N, De Camillis C, Ardente F, Pant R (2014) Allocation solutions for secondary material production and end of life recovery: proposals for product policy initiatives. Resour Conserv Recycl 88:1-12. https://doi. org/10.1016/j.resconrec.2014.03.016

Balafoutis AT, Koundouras S, Anastasiou E, Fountas S, Arvanitis K (2017) Life cycle assessment of two vineyards after the application of precision viticulture techniques: a case study. SustainabilityBasel 9(11):1997. https://doi.org/10.3390/su9111997

Birkved M, Hauschild MZ (2006) PestLCI - a model for estimating field emissions of pesticides in agricultural LCA. Ecol Model 198(3):433-451. https://doi.org/10.1016/j.ecolmodel.2006.05.035

Blonk Consultants (2014) Agri-footprint description of data. V 1.0. Retrieved from: www.agri-footprint.com/assets/Agri-FootprintPart2-DescriptionofdataVersion1.0.pdf

Borken J, Patyk A, Reinhardt GA (1999) Basisdaten für ökologishe Bilanzierungen - Einsatz von Nutzfahrzeugen, in Transport. Landwirtshaft und Bergbau. Friedr. Vieweg \& Sohn Publishers, Braunschweig/Wiesbaden, Germany

Borken-Kleefeld J, Weidema BP (2013) Global default data for freight transport per product group. Manuscript for special ecoinvent 3.0 issue of the Int J Life Cycle Ass

Brentrup F, Küsters J, Lammel J, Kuhlmann H (2000) Methods to estimate on-field nitrogen emissions from crop production as an input to LCA studies in the agricultural sector. Int J Life Cycle Ass 5(6):349. https://doi.org/10.1007/BF02978670

Davis J, Haglund C (1999) Life cycle inventory (LCI) of fertiliser production. fertiliser products used in Sweden and Western Europe. SIK-Report No. 654. Masters Thesis, Chalmers University of Technology

De Beaufort-Langeveld AS, Bretz R, Hischier R, Huijbregts M, Jean P, Tanner T, van Hoof G (2003) Code of life-cycle inventory practice. Society of Environmental Toxicology and Chemistry (SETAC)

Del Nobile MA, Baiano A, Conte A, Mocci G (2005) Influence of protein content on spaghetti cooking quality. J Cereal Sci 41(3):347356. https://doi.org/10.1016/j.jcs.2004.12.003

Dresen B, Jandewerth M (2012) Integration of spatial analyses into LCA - calculating GHG emissions with geoinformation systems. 
Int J Life Cycle Ass 17(9):1094-1103. https://doi.org/10.1007/ s11367-011-0378-3

Drivsholm T, Holm-Petersen M, Skårup S, Frees N, Olsen S (2002) Produkters forbrug af transport. Systemanalyse. København: Danish Environmental Protection Agency. (Arbejdsrapport fra Miljøstyrelsen no. 44)

EC (2007) Eurostat statistical books: "The use of plant protection products in the European Union” 1992-2003, 2007th edn. European Commission, Brussels

EC (2010) International Reference Life Cycle Data System (ILCD) Handbook-general guide for life cycle assessment-detailed guidance. European Commission, Joint Research Centre, Institute for Environment and Sustainability, Luxembourg

Ecoinvent (2021) https://www.ecoinvent.org/ Accessed 7 February 2021

Elgowainy A, Dieffenthaler D, Sokolov V, Sabbisetti R, Cooney C, Anjum A (2013) GREET Life-cycle model v1.1. US department of Energy - Argonne national laboratory

EPD (2019) Environmental Products Declarations. International. General Programme Instructions for the International EPD® System. Version 3.01. www.environdec.com

EU (2013) 2013/179/EU. European Commission Recommendation of 9 April 2013 on the use of common methods to measure and communicate the life cycle environmental performance of products and organisations

FAO (2011) Global food losses and food waste extent, causes and prevention. The Food and Agriculture Organization of the United Nations, Rome

FAO (2015) FertiStat - Fertilizer Use Statistics. The Food and Agriculture Organization of the United Nations, Rome

FEFAC (2015) European Feed Manufacturers' Federation - PEF screening report in the context of the EU Product Environmental Footprint Category Rules (PEFCR) Pilots - feed for food producing animals. Draft version 2.0 for EF Steering Committee. European Feed Manufacturers' Federation. October 2015

Frees N, Weidema BP (1998) Life cycle assessment of packaging systems for beer and soft drinks: energy and transport scenarios. Environmental Project no. 406. Danish Environmental Protection Agency

Freiermuth R (2006) Modell zur Berechnung der Schwermetallflüsse in der Landwirtschaftlichen Ökobilanz. Agroscope FAL Reckenholz, 42 p., Available at www.agroscope.admin.ch

Frischknecht R, Jungbluth N, Althaus HJ, Doka G, Dones R, Heck T, Hellweg S, Hischier R, Nemecek T, Rebitzer G, Spielmann M (2005) The ecoinvent database: overview and methodological framework (7 pp). Int J Life Cycle Ass 10(1):3-9. https://doi.org/ 10.1065/lca2004.10.181.1

Fritter M, Lawrence R, Marcolin B, Pelletier N (2020) A survey of life cycle inventory database implementations and architectures, and recommendations for new database initiatives. Int J Life Cycle Ass 25(8):1522-1531. https://doi.org/10.1007/s11367-020-01745-5

Gac A, Cariolle M, Deltour L, Dollé J-B, Espagnol S, Flénet F, Guingand N, Lagadec S, Le Gall A, Lellahi A, Malaval C, Ponchant P, Tailleur A (2010) GESTIM: Guide méthodologique pour l'estimation des impacts des activités agricoles sur l'effet de serre, version 1.2, Juin 2010. CASDAR $n^{\circ} 6147$

Gheewala SH, Jungbluth N, Notarnicola B, Ridoutt B, van der Werf $\mathrm{H}$ (2020) No simple menu for sustainable food production and consumption. Int J Life Cycle Ass 25(7):1175-1182. https://doi. org/10.1007/s11367-020-01783-z

Guinée JB, Lindeijer E (Eds.) (2002) Handbook on life cycle assessment: operational guide to the ISO standards (Vol. 7). Springer Science \& Business Media

Gustavsson J, Cederberg C, Sonesson U, Van Otterdijk R, Meybeck A (2013) The methodology of the FAO study: "Global Food Losses and Food Waste - extent, causes and prevention - FAO 2011
Heijungs R, De Koning A, Suh S, Huppes G (2006) Toward an information tool for integrated product policy: requirements for data and computation. J Ind Ecol 10(3):147-158. https://doi.org/10. 1162/jiec.2006.10.3.147

Hong C, Jin X, Ren J, Gu Z, Zhou Y (2019) Satellite data indicates multidimensional variation of agricultural production in land consolidation area. Sci Total Env 653:735-747. https://doi.org/ 10.1016/j.scitotenv.2018.10.415

IFA (2020) Statistical information. Retrieved from https://www.ifastat. org/databases/supply-trade. Accessed 15 April 2021

IPCC (1997) Greenhouse gas inventories. Revised 1996 IPCC guidelines for national greenhouse gas inventories. Available on-line: https://www.ipcc.ch/report/revised-1996-ipcc-guidelines-fornational-greenhouse-gas-inventories/. Accessed 10 May 2021

IPCC (2019) 2019 Refinement to the 2006 IPCC guidelines for national greenhouse gas inventories (IPCC). N2O emissions from managed soils, and $\mathrm{CO}_{2}$ emissions from lime and urea application, vol. 4, pp. 1-48 (Chapter 11)

ISO (2006a) ISO 14040:2006. Environmental management - life cycle assessment - principles and framework. International Organization for Standardisation

ISO (2006b) ISO 14044:2006. Environmental management - life cycle assessment - requirements and guidelines. International Organization for Standardisation

ISO (2006c) ISO 14025:2006. Environmental labels and declarations - type III environmental declarations - principles and procedures. International Organization for Standardisation

ISTAT (2021) Istituto Nazionale di Statistica. https://www.istat.it/. Accessed 12 April 2021

JRC (2010) JRC-IES, \& European Commision. ILCD handbook specific guide for life cycle inventory data sets

Jungbluth N, Chudacoff M, Dauriat A et al (2007) Life cycle inventories of bioenergy, Ecoinvent report version 2.0, Vol. 17. Swiss Centre for LCI, ESU. Dübendorf and Uster

Koch P, Salou T (2020) AGRIBALYSE®: methodology, agricultural stage - version 3.0. June 2020. Ed ADEME.Angers. France

Kongshaug G (1998) Energy consumption and greenhouse gas emissions in fertilizer production. In proc. of IFA Technical Conference, Marrakeck, Morocco, 28 September-1 October 1998

Kupfer T, Baitz M, Colodel C, Kokborg M, Schöll S, Rudolf M, Bos U, Bosch F, Gonzalez M. Schuller O, Hengstler J, Stoffregen A, Thylmann D (2020) GaBi databases \& modeling principles. Available at: www.gabi-software.com.

Maier M, Mueller M, Yan X (2017) Introducing a localised spatiotemporal LCI method with wheat production as exploratory case study. J Clean Prod 140:492-501. https://doi.org/10.1016/j.jclepro. 2016.07.160

Marras MF, De Leo S, Giuca S, Macrì MC, Sardone R, Viganò L (2020) L'agricoltura Italiana Conta 2020. Rapporto CREA. Available at: https://www.crea.gov.it/web/politiche-e-bioeconomia/lagricoltura-italiana-conta- 2020

Meinshausen I, Müller-Beilschmidt P, Viere T (2016) The EcoSpold 2 format - why a new format? Int J Life Cycle Ass 21(9):12311235. https://doi.org/10.1007/s11367-014-0789-z

Milà i Canals L, Muñoz I, Hospido A, Plassmann K, McLaren SJ, Edwards-Jones G, Hounsome B (2008) Life cycle assessment (LCA) of domestic vs. imported vegetables. Case studies on broccoli, salad crops and green beans. CES Working Papers 01/08

Nemecek T, Bengoa X, Lansche J, Roesch A, Faist-Emmenegger M, Rossi V, Humbert S (2019) Methodological guidelines for the life cycle inventory of agricultural products. Version 3.5, December 2019. World Food LCA Database (WFLDB). Quantis and Agroscope, Lausanne and Zurich, Switzerland

Nemecek T, Schnetzer J (2012) Methods of assessment of direct field emissions for LCIs of agricultural production systems. Final 
Report Ecoinvent v3.0. Swiss Centre for Life Cycle Inventories, Dübendorf, Switzerland

Nguyen TTH, Bouvarel I, Ponchant P, van der Werf HMG (2012) Using environmental constraints to formulate low-impact poultry feeds. J Clean Prod 28:215-224. https://doi.org/10.1016/j.jclepro.2011. 06.029

Nielsen PH, Nielsen AM, Weidema BP, Dalgaard R, Halberg N (2003) LCA Food Data Base. www.lcafood.dk

Niero M, Olsen SI (2016) Circular economy: to be or not to be in a closed product loop? A life cycle assessment of aluminium cans with inclusion of alloying elements. Resour Conserv Recycl 114:18-31. https://doi.org/10.1016/j.resconrec.2016.06.023

Nitschelm L, Aubin J, Corson MS, Viaud V, Walter C (2016) Spatial differentiation in life cycle assessment LCA applied to an agricultural territory: current practices and method development. J Clean Prod 112:2472-2484. https://doi.org/10.1016/j.jclepro. 2015.09.138

Notarnicola B, Tassielli G, Renzulli P (2012) Modeling the agri-food industry with life cycle assessment. In: Curran M.A. Life cycle assessment handbook. p. 159-184, New York: Wiley, ISBN: 9781118099728

Notarnicola B, Salomone R, Petti L, Renzulli PA, Rocco R, Cerutti AK (2015) Life cycle assessment in the agri-food sector - case studies. Springer International Publishing, Switzerland, Methodological issues and best practices

Notarnicola B, Sala S, Anton A, McLaren SJ, Saouter E, Sonesson U (2017) The role of life cycle assessment in supporting sustainable agri-food systems: a review of the challenges. J Clean Prod 140:399-409. https://doi.org/10.1016/j.jclepro.2016.06.071

Pergola M, Favia M, Palese AM, Perretti B, Xiloyannis C, Celano $\mathrm{G}$ (2013) Alternative management for olive orchards grown in semi-arid environments: An energy, economic and environmental analysis. Scientia Horticulturae, 162, 380-386

Pfister S, Bayer P (2014) Monthly water stress: spatially and temporally explicit consumptive water footprint of global crop production. $\mathbf{J}$ Clean Prod 73:52-62. https://doi.org/10.1016/j.jclepro.2013.11. 031

Pfister S, Baumann J (2012) Monthly characterization factors for water consumption and application to temporally explicit cereals inventory. In Proceedings of the 8th international conference on life cycle assessment in the agri-food sector (LCA Food 2012) (pp. $1-4)$

Pinsonnault A, Lesage P, Levasseur A, Samson R (2014) Temporal differentiation of background systems in LCA: relevance of adding temporal information in LCI databases. Int J Life Cycle Ass 19(11):1843-1853. https://doi.org/10.1007/s11367-014-0783-5

Prasuhn V (2006) Erfassung der PO4-Austräge für die Ökobilanzierung - SALCA-Phosphor. Agroscope FAL Reckenholz, Zürich, 22 p., Available at: www.agroscope.admin.ch

Quantis (2020) World Food LCA Database WFLDB. SimaPro. https:// simapro.com/products/quantis-world-food-lca-database/

Ribaudo F (2017) Prontuario di agricoltura: ordinamenti colturali, aziende agricole, fabbricati rurali, cure colturali e tempi di lavoro, coltivazioni e allevamenti, selvicoltura e cantieri forestali, prezzario. 2nd Edition. Hoepli, Milan, Italy

Rinaldi M, Stadler E (2002) Trends im Abgasverhalten landwirtschaftlicher Traktoren: neue Modelle deutlich sauberer. FAT

Roches A, Nemecek T, Gaillard G, Plassmann K, Sim S, King H, Milà I, Canals L (2010) MEXALCA: a modular method for the extrapolation of crop LCA. Int J Life Cycle Ass 15(8):842-854. https://doi. org/10.1007/s11367-010-0209-y

Roos Lindgreen E, Mondello G, Salomone R, Lanuzza F, Saija G (2021) Exploring the effectiveness of grey literature indicators and life cycle assessment in assessing circular economy at the micro level: a comparative analysis. Int J Life Cycle Ass. https:// doi.org/10.1007/s11367-021-01972-4

Röös E, Sundberg C, Hansson PA (2010) Uncertainties in the carbon footprint of food products: a case study on table potatoes. Int J Life Cycle Ass 15(5):478-488. https://doi.org/10.1007/ s11367-010-0171-8

Ruviaro CF, Gianezini M, Brandao FS, Winck CA, Dewes H (2012) Life cycle assessment in Brazilian agriculture facing worldwide trends. J Clean Prod 12(28):9-24. https://doi.org/10.1016/j.jclepro.2011. 10.015

Sala S, Anton A, McLaren SJ, Notarnicola B, Saouter E, Sonesson U (2017) In quest of reducing the environmental impacts of food production and consumption. J Clean Prod 140:387-398. https:// doi.org/10.1016/j.jclepro.2016.09.054

Salmon-Monviola J, Durand P, Ferchaud F, Oehler F, Sorel L (2012) Modelling spatial dynamics of cropping systems to assess agricultural practices at the catchment scale. Comput Electron Agr 81:1-13. https://doi.org/10.1016/j.compag.2011.10.020

Sonesson U, Janestad H, Raaholt B (2003) Energy for preparation and storing of food - models for calculation of energy use for cooking and cold storage in households. 709 2003, 1-56. 2003. SIK, Gothenburg, Sweden

Tassielli G, Renzulli PA, Mousavi-Avval SH, Notarnicola B (2019) Quantifying life cycle inventories of agricultural field operations by considering different operational parameters. Int J Life Cycle Ass 24(6):1075-1092. https://doi.org/10.1007/s11367-018-1553-6

Udo de Haes H (2006) How to approach land use in LCIA or, how to avoid the Cinderella effect? Int J Life Cycle Ass 11:219-221. https://doi.org/10.1065/lca2006.07.257

Vellinga TV, Blonk H, Marinussen M, van Zeist WJ, Starmans DAJ (2013) Methodology used in FeedPrint: a tool quantifying greenhouse gas emissions of feed production and utilization. (Report / Wageningen UR Livestock Research; No. 674). Wageningen UR Livestock Research. https://edepot.wur.n1/254098

Weidema B, Wesnaes MS (1996) Data quality management for life cycle inventories - an example of using data quality indicators. J Clean Prod 4(3-4):167-174. https://doi.org/10.1016/S09596526(96)00043-1

Wernet G, Bauer C, Steubing B, Reinhard J, Moreno-Ruiz E, Weidema B (2016) The Ecoinvent database version 3 (part I): overview and methodology. Int J Life Cycle Ass 21(9):1218-1230. https://doi. org/10.1007/s11367-016-1087-8

Williams AG, Audsley E, Sandars DL (2006) Determining the environmental burdens and resource use in the production of agricultural and horticultural commodities. Main Report. Defra Research Project IS0205. Bedford: Cranfield University and Defra. Available at: http://randd.defra.gov.uk/Default.aspx?Module=More \&Location $=$ None \&ProjectID $=11442$

Xu X, Lan Y (2017) Spatial and temporal patterns of carbon footprints of grain crops in China. J Clean Prod 146:218-227. https://doi. org/10.1016/j.jclepro.2016.11.181

Yang Y, Tao M, Suh S (2018) Geographic variability of agriculture requires sector-specific uncertainty characterization. Int J Life Cycle Ass 23(8):1581-1589. https://doi.org/10.1007/ s11367-017-1388-6

Yi I, Itsubo N, Inaba A, Matsumoto K (2007) Development of the interregional I/O based LCA method considering region-specifics of indirect effects in regional evaluation. Int J Life Cycle Ass 12(6):353-364. https://doi.org/10.1065/lca2007.06.339

Publisher's Note Springer Nature remains neutral with regard to jurisdictional claims in published maps and institutional affiliations. 


\section{Authors and Affiliations}

B. Notarnicola ${ }^{1}$ - G. Tassielli ${ }^{1}$ P. A. Renzulli ${ }^{1}$ (I) R. Di Capua ${ }^{1}$ - G. Saija ${ }^{2} \cdot$ R. Salomone ${ }^{2} \cdot$ P. Primerano ${ }^{2} \cdot$ L. Petti ${ }^{3}$. A. Raggi ${ }^{3} \cdot$ N. Casolani ${ }^{3} \cdot$ A. Strano ${ }^{4} \cdot$ M. Mistretta $^{4}$

1 Ionian Department of Law, Economics and Environment, Università Degli Studi Di Bari Aldo Moro, Bari, Italy

2 Department of Economics, Università Degli Studi Di Messina, Messina, Italy
3 Department of Economic Studies, Università degli Studi "G. d'Annunzio" di Chieti - Pescara, Chieti, Italy

4 Department of Agriculture, Università Degli Studi Mediterranea Reggio Calabria, Reggio Calabria, Italy 